\title{
Boxidine Hydrochloride
}

National Cancer Institute

\section{Source}

National Cancer Institute. Boxidine Hydrochloride. NCI Thesaurus. Code C91026.

The hydrochloride salt form of boxidine, an agent that inhibits the transformation of 7dehydrocholesterol to cholesterol and also inhibits sterol absorption. 